\title{
Synthesis of the two male specific volatiles released by Edessa meditabunda (Heteroptera: Pentatomidae)
}

\author{
Diogo Montes Vidal, Carla F. Fávaro and Paulo Henrique G. Zarbin*
}

Federal University of Paraná, Department of Chemistry, 81531-990, Curitiba-PR, Brazil

*pzarbin@ufpr.br

Keywords: Pheromone, Grignard Isocyanate

\section{INTRODUCTION}

Brazil is one of the major soybean producers in the world. In the piercing-sucking complex that occurs in soybean crops, Edessa meditabunda is considered a secondary pest. Recent studies from our research group showed the presence of two male-specific compounds which were EAD active in females. Analysis of GC-MS and GC-FTIR spectra of these compounds suggested that they were both methyl branched long chain methyl esters. The methyl ester structures were proposed based on the mass spectra (EI) of the respective hydrocarbons obtained by microderivatizations, as being methyl 4,8,12trimethylpentadecanoate (1) (major) and methyl 4,8,12-trimethyltetradecanoate (minor) (2).<smiles>[R]CCC(C)CCCC(C)CCCC(C)CCCC(C)OC</smiles>
(1) $\mathrm{R}=\mathrm{CH}_{3}$
(2) $\mathrm{R}=\mathrm{H}$

Figure 1. Male-specific compounds released by $E$. meditabunda.

\section{RESULTS AND DISCUSSION}

A synthetic route (Scheme 1) to obtain the compounds (1) and (2) was proposed starting from the reaction between methylcyclopropylketone (3) and bromopropane or bromo ethane, employing a sequence of Grignard and Julia reactions ${ }^{1}$ that was repeated three times to obtain a bromide containing the methyl branches on the same position as found on the natural pheromone. After some organic function modifications, the racemic methyl 4,8,12trimethylpentadecanoate (1) and methyl 4,8,12trimethyltetradecanoate (2) were obtained in 5,6\% and $7,2 \%$ yield respectively after 11 steps. The chromatographic profile, mass and infrared spectra of the synthetic standard were identical to the major component. To stablish the absolute configuration of the natural pheromone, microderivatizations using the alcohol derivative from the insect extract (6) and (S)-(+)-1-(1-nafthyl)-ethyl isocianate (7) forming the carbamate (8) are underway and will be analyzed by chiral HPLC (Scheme 2).

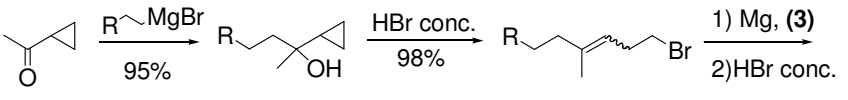

(3)

(4)

(5)<smiles>[R]CC/C(C)=C/CC/C(C)=C/CCBr</smiles>

(6)

(7)
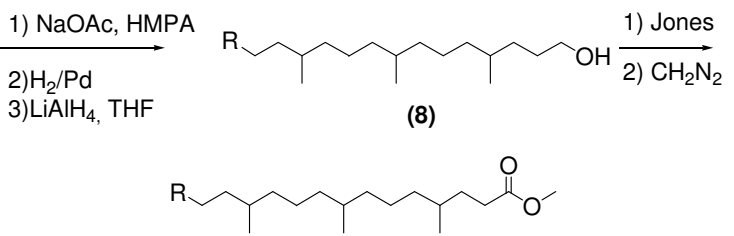

(1) $\mathrm{R}=\mathrm{CH}_{3}$

(2) $\mathrm{R}=\mathrm{H}$

Scheme 1. Synthetic route to obtain the major component (1).
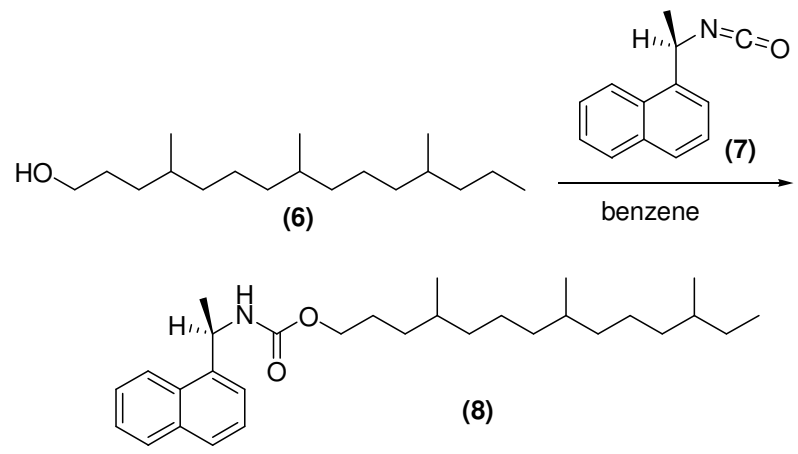

Scheme 2. Microderivatization with and $(S)-(+)-1-(1-$ nafthyl)-ethyl isocianate (7).

\section{CONCLUSION}

The synthesis of the two male specific compounds released by $E$. meditabunda was useful to confirm the structures initially proposed.

\section{ACKNOWLEDGEMENTS}

We thank the Instituto Nacional de Ciência e Tecnologia de Semioquímicos na Agricultura (INCT) for the financial support.

\section{REFERENCES}

${ }^{1}$ Mori, K; Murata, N Liebigs Annalen der Chemie. 1994, 6, 637. 